\title{
Visual and Hormone Outcomes in Pituitary Apoplexy: Results of a Single Surgeon, Single Institution 15-Year Retrospective Review and Pooled Data Analysis
}

\author{
Scott C. Seaman ${ }^{1}$ Mark C. Dougherty ${ }^{1}$ Mario Zanaty ${ }^{1}$ Leslie A. Bruch ${ }^{2}$ Scott M. Graham ${ }^{3}$ \\ Jeremy D. W. Greenlee ${ }^{1}$ \\ ${ }^{1}$ Department of Neurosurgery, University of lowa Hospitals and \\ Clinics, lowa City, lowa, United States \\ ${ }^{2}$ Department of Pathology, University of lowa Hospitals and Clinics, \\ lowa City, lowa, United States \\ ${ }^{3}$ Department of Otolaryngology, University of lowa Hospitals and \\ Clinics, lowa City, lowa, United States

\begin{abstract}
Address for correspondence Jeremy Greenlee, MD, Department of Neurosurgery, University of lowa Hospitals and Clinics, 200 Hawkins Drive, lowa City, IA 52242, United States (e-mail: jeremy-greenlee@uiowa.edu).
\end{abstract}

J Neurol Surg B Skull Base 2021;82:392-400.

\section{Abstract}

Keywords

- hormone dysfunction

- hypopituitarism

- vision outcomes

- aggressive early surgery

- timing of surgery

- pooled analysis

Introduction Pituitary apoplexy commonly presents with visual and hormonal deficits. While traditionally regarded as an emergency, there have been increasing trends toward conservative management. Our institutional practice consists of early surgery; therefore, we reviewed our series evaluating vision outcomes, hormone function, and complications compared with the present literature.

Methods We retrospectively reviewed our institution's medical records to identify pituitary apoplexy patients who were treated via the endoscopic endonasal approach by a single neurosurgeon (senior author). We recorded basic demographics, radiographic and operative features, and preoperative and postoperative vision and hormone status. Univariate and multivariate statistical analyses were performed. Pooled data analysis of visual outcomes in the current literature using Bayesian inference was performed.

Results We identified 44 patients with histologically confirmed pituitary apoplexy treated by endoscopic transsphenoidal decompression; $77 \%$ were treated within 24 hours of presentation. Total $45 \%$ had cranial nerve (CN) palsy, 36\% anopsia, and $20 \%$ had visual acuity deficits. Postoperatively, $100 \%$ of CN palsies improved, $81 \%$ of anopsias improved, and $66.7 \%$ of visual acuity deficits improved. Long-lasting panhypopituitarism (25\%) and hypothyrodism (22\%) were common. Cavernous sinus involvement predicted residual tumor $(p=0.006)$. Pooled Bayesian inference showed $30 \%$ improvement in vision outcomes with surgical management compared with medical management with a number needed to treat of 3.3.

Conclusion Early surgery for pituitary apoplexy was associated with excellent visual outcomes and the need for long-term hormone replacement is common. Cavernous sinus involvement is an independent predictor of residual tumor. Pooled statistical analysis favors aggressive surgical management of apoplexy for improved visual outcomes.
\end{abstract}

received

January 20, 2020

accepted

April 12, 2020

published online

June 19, 2020 (c) 2020. Thieme. All rights reserved.

Georg Thieme Verlag KG,

Rüdigerstraße 14,

70469 Stuttgart, Germany
DOI https://doi.org/

10.1055/s-0040-1713104. ISSN 2193-6331. 


\section{Introduction}

Pituitary apoplexy is a rare event associated with hemorrhage or infarction of a pituitary neoplasm, most commonly an adenoma. The incidence of apoplexy in the general population is estimated at 6.2 per $100,000^{1}$ and affects 2 to $12 \%$ of pituitary adenomas. ${ }^{2,3}$ Common chief complaints include severe headache, visual abnormalities, or altered mental status; visual deficits and hormone abnormalities are frequently seen on physical exam and laboratory studies. Visual signs and symptoms result from compression of the optic apparatus and cranial nerves (CNs) III, IV, and VI, all of which sit in close anatomic proximity to the pituitary gland. Hormonal abnormalities result from direct disruption of the pituitary's critical endocrinological functions. Although these hormonal deficits can be life threatening if untreated, oftentimes they can be managed with chronic hormone replacement therapy under the guidance of an endocrinologist.

The rarity of pituitary apoplexy makes studying its treatment in a prospective fashion challenging. Thus, management decisions are guided primarily by retrospective case series and clinical experience. Some providers consider pituitary apoplexy a neurosurgical emergency, ${ }^{3,4}$ while others argue in favor of medical management alone. ${ }^{5-7}$ The timing of surgery after symptom onset is also controversial, with some experts advocating for surgical decompression within 72 hours of onset, yet others argue that delayed surgical management is acceptable. ${ }^{5,7-20}$ Multiple published papers have reported outcomes for surgical management, medical management, or some combination of both; however, given that all available data are retrospective, directly comparing these outcomes is subject to selection and other biases. For example, patients with severe visual deficits at presentation tend to be treated surgically, which confounds vision recovery comparison between groups. As such, recommendations for treatment protocols in the existing literature vary greatly.

Here, we present our single-institution, single-neurosurgeon case series, and clinical outcomes for patients with pituitary apoplexy treated with endoscopic transsphenoidal surgery over a 15-year period (2005-2019). We do not report nonsurgical cases of pituitary apoplexy because nearly all cases are treated surgically at our institution and we desired histological confirmation of the diagnosis as some cases can appear radiologically similar to other pituitary pathologies such as Rathke's cleft cysts or cystic adenomas. To augment our data, we also performed a Bayesian statistical analysis of our data pooled with the extant literature to assess the probability of improvement in vision with surgery versus no surgery. Except for our sellar repair technique, our treatment approach to pituitary apoplexy has remained the same over the 15-year period.

\section{Methods}

\section{Database Formulation and Data Collection}

We retrospectively reviewed our patient series from 2005 to 2019 after appropriate institutional review board approval. All patients were evaluated and treated at the University of Iowa
Hospitals and Clinics, and all surgeries were performed via the endoscopic endonasal transsphenoidal approach by a single staff surgeon (senior author) with assistance from otolaryngology. We queried our pathology databases for "pituitary adenoma" and "hemorrhage," "pituitary adenoma" and "infarct and/or ischemic" and "pituitary apoplexy." We then reviewed the clinical presentations such that all cases were clinically and pathologically confirmed apoplexy. Data were extracted into a de-identified database. Preoperative and postoperative data regarding hormone function were defined based on serologic studies. Vision parameters ( $\mathrm{CN}$ palsies, visual acuity [VA], and visual fields [VF]) were collected based on neurosurgical and ophthalmologic evaluation, including Snellen chart during formal ophthalmologic evaluation except when deficits were such that emergent surgical intervention was necessary. Hormone and vision data were recorded as an abnormality being present or absent. Tumor volume and extent of resection were calculated based on available preoperative and postoperative MR or CT scans using Vitrea, a 3D volumetric analysis software (Vitrea by Vital Imaging version 6.7, Minnetonka, Minnesota, United States).

\section{Statistical Analysis}

Basic statistics and univariate and multivariate analyses were performed using GraphPad Prism for Mac(version 7.0c, GraphPad Software, La Jolla, California, United States) and Python 3.0 (Anaconda, Spyder 3.3.3). Features with $p$-values $<0.20$ on univariate analysis were included in the multivariate analysis. A logistic regression model was performed for categorical targets, and a multivariate linear regression model was used for numerical targets. Categorical features were transformed to dummy variables. Standardization was performed for numerical variables. The multivariate linear regression was performed when the data were linear (if not, a log transformation or scaling was performed); there was no heteroscedasticity and no autocorrelation. We tested for autocorrelation through the Durbin-Watson test (accepted values between 1 and 3) and for multicollinearity through the variance inflation factor, excluding features with a factor $>6$.

For the pooled statistical analysis, we retrieved data from the most recent meta-analysis that compared medical versus surgical treatment, who collected the studies according to the standard PRISMA and Cochrane methodologies. ${ }^{21}$ Their inclusion criteria were studies published in English that focused on outcomes of both surgical and conservative management. The probabilities from the meta-analysis served as priors. We performed Bayesian inference assuming a fixed-effect model. The 95\% highest posterior distribution (HPD) was computed using Markov Chain Monte Carlo algorithm. PyMC 3.6 (Python 3.7) was used for Bayesian inference.

\section{Results}

\section{Demographics of Pituitary Apoplexy}

Over a 15-year period, we identified 44 patients, 20 females and 24 males with median age of 55 years (range $=12-82$ ). Mean length of follow-up was 41 months (median $=37$ months; range $=1-132$ months). The mean BMI was 34.8 
Table 4 Univariate analysis

\begin{tabular}{|c|c|c|c|c|c|}
\hline Outcomes predictors & Residual volume & $\begin{array}{l}\text { Extent of } \\
\text { resection }\end{array}$ & $\begin{array}{l}\text { Postoperative } \\
\text { panhypopit }\end{array}$ & $\begin{array}{l}\text { Postoperative } \\
\text { hypocortisolism }\end{array}$ & $\begin{array}{l}\text { Length } \\
\text { of stay }\end{array}$ \\
\hline Age & 2013 & 2013; & $3.824(0.057)$ & - & - \\
\hline BMI & 2013; & - & $3.452(0.070)$ & - & - \\
\hline Chronic anticoagulation & 2013; & 2013; & $3.532(0.067)$ & $8.016(0.007)$ & $13.312(0.001)$ \\
\hline Tumor volume & $13.522(0.0001)$ & 2013; & 2013 & - & - \\
\hline Pituitary infarction & 2013; & 2013; & $2.865(0.098)$ & - & - \\
\hline Cavernous sinus involvement & $5.890(0.019)$ & 2013; & 2013; & - & - \\
\hline CSF leak & 2013 & 2013; & 2013; & - & $5.407(0.025)$ \\
\hline Postoperative visual acuity deficit & 2013; & 2013; & 2013; & - & $4.711(0.035)$ \\
\hline
\end{tabular}

Abbreviations: BMI, body mass index; CSF, cerebrospinal fluid.

Findings reported as odds ratio ( $p$-value), where (-) was no significance. The first column represents the independent variables and the first row represents the dependent variables in the analysis. The bolded values indicate significance $(p<0.05)$, while italicized signified trends toward significance $(p<0.10)$.

(range $=21.6-49.2$ ). Hypertension and diabetes were the most common medical comorbidities, followed by coronary artery disease and obstructive sleep apnea. Total $9 \%$ of subjects were on anticoagulation (i.e., warfarin) and $27 \%$ were on aspirin; no subjects took clopidogrel or any other antiplatelet agent (-Table 1).

\section{Preoperative Features}

The most common presenting symptoms were headache(91\%) and visual abnormalities (68\%). Altered mental status was present in 16\% (-Table 1). Formal ophthalmologic evaluation was available for all patients. Total $36 \%$ had a VF deficit based on confrontation, and $20 \%$ had a VA deficit. Cranial neuropathy was present in $45 \%$, of which a third nerve palsy was common (41\% of subjects) as was the involvement of multiple nerves within patients (-Table 2). There was a wide variety of preoperative hormonal abnormalities, the most common being hypothyroidism (37\%; - Table 3). Testosterone was below normal in $25 \%$ of patients on the preoperative hormonal panel, consisting of $46 \%$ of our male patients.

\section{Radiographic Features}

The mean preoperative tumor volume was $8.6 \mathrm{~cm}^{3}$. Suprasellar extension was present in $93 \%$ of patients, and $45 \%$ had cavernous sinus involvement. Carotid encasement was evident in $34 \%$ of patients. A hemorrhagic component was identified in 75 versus $18 \%$ depicting ischemia; $7 \%$ had components of both hemorrhage and ischemia ( - Table $\mathbf{1}$ ). Univariate analysis ( - Table 4) showed cavernous sinus involvement $(p=0.019)$, and larger initial tumor volume $(p=0.0001)$ were associated with greater residual volume. Similarly, multivariate analysis (-Table 5) demonstrated that larger preoperative tumor volume $(p=0.001)$ and cavernous sinus involvement (odds ratio [OR]: $3.16, p=0.006$ ) were associated with larger residual tumor volume, which itself trended with a longer hospitalization $(p=0.084)$.

\section{Operative Features}

All cases had confirmed apoplectic tissue as evidenced by pituitary tissue with associated hemorrhage, necrosis or both, and the clinical presentation. The underlying pathology

Table 2 Preoperative and postoperative vision data

\begin{tabular}{|c|c|c|c|c|c|}
\hline \multirow[t]{7}{*}{ Preoperative vision related status } & \multicolumn{2}{|l|}{ Domain } & \multicolumn{3}{|l|}{$n(\%)$} \\
\hline & \multirow[t]{2}{*}{ Visual deficit } & Visual field & \multicolumn{3}{|l|}{$16(36 \%)$} \\
\hline & & Visual acuity & \multicolumn{3}{|l|}{$9(20 \%)$} \\
\hline & \multirow[t]{4}{*}{ Cranial neuropathy } & III & \multicolumn{3}{|l|}{$18(41 \%)$} \\
\hline & & IV & \multicolumn{3}{|l|}{$6(14 \%)$} \\
\hline & & $\mathrm{V}$ (any branch) & \multicolumn{3}{|l|}{$1(2 \%)$} \\
\hline & & $\mathrm{VI}$ & \multicolumn{3}{|l|}{$6(14 \%)$} \\
\hline \multirow[t]{5}{*}{ Postoperative vision related status } & \multirow[t]{2}{*}{ Domain } & \multicolumn{4}{|c|}{ Distribution of change } \\
\hline & & Resolved & Remain & Acquired & Preoperatively normal \\
\hline & Visual field & 13 & 3 & 0 & 28 \\
\hline & Visual acuity & 6 & 3 & 0 & 35 \\
\hline & Cranial neuropathies & 20 & 0 & 0 & 24 \\
\hline
\end{tabular}


Table 3 Hormone findings and outcomes

\begin{tabular}{|c|c|c|c|c|c|}
\hline \multirow{15}{*}{$\begin{array}{l}\text { Preoperative } \\
\text { hormone status }\end{array}$} & Hormonal abnormalities & \multicolumn{4}{|l|}{$n(\%)$} \\
\hline & Functional adenomas & \multicolumn{4}{|c|}{$6 / 44(12 \%)$} \\
\hline & Prolactin-prolactinoma & \multicolumn{4}{|l|}{$6(14 \%)$} \\
\hline & Prolactin-stalk effect & \multicolumn{4}{|l|}{$5(11 \%)$} \\
\hline & Hypothyroidism & \multicolumn{4}{|l|}{$18(41 \%)$} \\
\hline & Low IGF-1 & \multicolumn{4}{|l|}{$4(9 \%)$} \\
\hline & Elevated IGF-1 (nonfunctional, no acromegaly) & \multicolumn{4}{|l|}{$3(7 \%)$} \\
\hline & Hypocortisolism & \multicolumn{4}{|l|}{$8(18 \%)$} \\
\hline & Low testosterone & \multicolumn{4}{|l|}{$11(25 \%)$} \\
\hline & Panhypopituitarism & \multicolumn{4}{|l|}{$2(5 \%)$} \\
\hline & Presenting number of hormone abnormalities & \multicolumn{4}{|l|}{$\mathrm{n}(\%)$} \\
\hline & 0 Abnormalities & \multicolumn{4}{|l|}{$4(9 \%)$} \\
\hline & 1 Abnormality & \multicolumn{4}{|l|}{$16(36 \%)$} \\
\hline & 2 Abnormalities & \multicolumn{4}{|l|}{$11(25 \%)$} \\
\hline & $3+$ Abnormalities & \multicolumn{4}{|l|}{$13(30 \%)$} \\
\hline \multirow{19}{*}{$\begin{array}{l}\text { Postoperative } \\
\text { hormone status }\end{array}$} & Hormone abnormalities & \multicolumn{4}{|c|}{ Distribution of change } \\
\hline & & Resolved & Unresolved & Acquired & $\begin{array}{l}\text { Unresolved/ } \\
\text { acquired cases } \\
(n, \%)\end{array}$ \\
\hline & Functional adenomas & 5 & 1 & 0 & $1(20 \%)$ \\
\hline & Prolactin-prolactinoma & 5 & 1 & 0 & $1(20 \%)$ \\
\hline & Prolactin-stalk effect & 5 & 0 & 0 & $0(0 \%)$ \\
\hline & Hypothyroidism & 14 & 4 & 7 & $11(22 \%)$ \\
\hline & Low IGF-1 & 4 & 0 & 0 & $0(0 \%)$ \\
\hline & Elevated IGF-1 (nonfunctional, no acromegaly) & 3 & 0 & 0 & $0(0 \%)$ \\
\hline & Hypocortisolism & 6 & 2 & 4 & $6(12 \%)$ \\
\hline & Low testosterone & 10 & 1 & 2 & $3(6 \%)$ \\
\hline & Panhypopituitarism & 1 & 1 & 10 & $11(25 \%)$ \\
\hline & Diabetes insipidus-transient & 0 & 0 & 8 & $8(18 \%)$ \\
\hline & Diabetes insipidus-permanent & 0 & 0 & 3 & $3(6 \%)$ \\
\hline & None & 0 & 4 & 10 & $14(29 \%)$ \\
\hline & Hormone abnormalities at follow-up & $n(\%)$ & & & \\
\hline & 0 Abnormalities & $12(27 \%)$ & & & \\
\hline & 1 Abnormality & $6(14 \%)$ & & & \\
\hline & 2 Abnormalities & $9(20 \%)$ & & & \\
\hline & $3+$ Abnormalities & $17(39 \%)$ & & & \\
\hline
\end{tabular}

Abbreviation: IGF, insulin-like growth factor.

in all cases was consistent with pituitary adenoma (-Table 1). For sellar reconstruction, 39\% of patients had an absorbable D- and L-lactide polymer plate (Resorb-X TSI, KLS Martin LP, Jacksonville, Florida, United States) utilized as a semirigid buttress, while in $43 \%$ a fat graft was utilized in reconstruction ( $\mathbf{- T a b l e} \mathbf{1}$ ). Fat grafts were used earlier in the series and plates were utilized for the latter half of patients reflecting a practice change. A nasoseptal flap was required in only two patients. Of the 44 patients, 34 underwent surgery within 24 hours of presentation, and 3 between 24 to 48 hours; the remaining 7 were operated on more than 7 days from symptom onset due to delayed presentation.

\section{Visual Outcomes}

All 20 patients with preoperative cranial neuropathy resolved following surgery at 6-month follow-up with most resolved at 6 weeks ( - Table 2 ). Of the nine patients with VA deficits preoperatively, six improved and three remained stable. In 17 patients with VF deficits preoperatively, 14 improved with 11 cases having complete resolution and 3 
Table 1 Demographic, clinical, radiographic features, tumor features, and treatment details at the time of presentation

\begin{tabular}{|c|c|c|}
\hline Category & Factor & Value \\
\hline \multirow[t]{4}{*}{ Demographics } & Total patients & 44 \\
\hline & Female gender, $n(\%)$ & $20(45 \%)$ \\
\hline & Median age (range) & $55(12-82)$ \\
\hline & Mean BMI (SD) & $34.8(7.5)$ \\
\hline \multirow{7}{*}{$\begin{array}{l}\text { Comorbidites } \\
(n, \%)\end{array}$} & Hypertension & $22(50 \%)$ \\
\hline & Diabetes mellitus & $13(30 \%)$ \\
\hline & Heat disease & $8(18 \%)$ \\
\hline & Aspirin use & $12(27 \%)$ \\
\hline & Anticoagulation & $4(9 \%)$ \\
\hline & Obstructive sleep apnea & $6(14 \%)$ \\
\hline & Prior resection & $3(7 \%)$ \\
\hline \multirow{5}{*}{$\begin{array}{l}\text { Presenting } \\
\text { symptoms } \\
(n, \%)\end{array}$} & Headache & $40(91 \%)$ \\
\hline & Vision related/complaint & $30(68 \%)$ \\
\hline & Altered mental status & $7(16 \%)$ \\
\hline & Nausea/vomiting & $7(16 \%)$ \\
\hline & Hormone-related complaint & $4(9 \%)$ \\
\hline \multirow{3}{*}{$\begin{array}{l}\text { Apoplexy } \\
\text { etiology } \\
\text { by imaging } \\
(n, \%)\end{array}$} & Hemorrhagic & $33(75 \%)$ \\
\hline & Ischemic & $8(18 \%)$ \\
\hline & Both & $3(7 \%)$ \\
\hline \multirow[t]{4}{*}{$\begin{array}{l}\text { Imaging } \\
\text { features }\end{array}$} & $\begin{array}{l}\text { Tumor volume }(\mathrm{cm}) \\
\text { mean, (SD) }\end{array}$ & $8.6(7.0)$ \\
\hline & Suprasellar extension, $n(\%)$ & $41(93 \%)$ \\
\hline & $\begin{array}{l}\text { Cavernous sinus } \\
\text { involvement, } n(\%)\end{array}$ & $20(45 \%)$ \\
\hline & Carotid encasement, $n$ (\%) & $15(34 \%)$ \\
\hline \multirow{3}{*}{$\begin{array}{l}\text { Histopathology } \\
(n, \%)\end{array}$} & Pituitary adenoma & $44(100 \%)$ \\
\hline & Functioning adenoma & $6(14 \%)$ \\
\hline & Nonfunctioning adenoma & $38(86 \%)$ \\
\hline Surgical factors & $\begin{array}{l}\text { Extent of resection, } \\
\text { mean \% (SD) }\end{array}$ & $78.1(17)$ \\
\hline \multirow{3}{*}{$\begin{array}{l}\text { Dural } \\
\text { reconstruction } \\
(n, \%)\end{array}$} & Resorb-X plate & $17(39 \%)$ \\
\hline & Fat graft \pm duragen & $19(43 \%)$ \\
\hline & Duragen only & $8(18 \%)$ \\
\hline \multirow{2}{*}{$\begin{array}{l}\text { Postoperative } \\
\text { factors }\end{array}$} & CSF leak, $n(\%)$ & $1(2 \%)$ \\
\hline & $\begin{array}{l}\text { Length of stay, } \\
\text { median (IQR) }\end{array}$ & $4(3-6)$ \\
\hline
\end{tabular}

Abbreviations: BMI, body mass index; CSF, cerebrospinal fluid; IQR, interquartile range; SD, standard deviation.

were stable; none had clinical worsening after surgery (-Table 2). We report visual outcomes as a function of timing of surgery (-Table $\mathbf{6}$ ) but very small subject numbers within these subgroups preclude statistical inferences.

\section{Hormonal Outcomes}

The majority of patients showed stable hormonal function after surgery compared with preoperative status with wide variation in postoperative hormonal abnormalities ( - Table 3 ).
Table 5 Multivariate analysis

\begin{tabular}{|l|l|l|}
\hline Outcomes predictors & $\begin{array}{l}\text { Residual } \\
\text { volume }\end{array}$ & $\begin{array}{l}\text { Length } \\
\text { of stay }\end{array}$ \\
\hline Chronic anticoagulation & - & $\begin{array}{l}6.434 \\
(0.011)\end{array}$ \\
\hline Tumor volume & 0.1245 & - \\
$(0.001)$ & 3.1623 & - \\
\hline $\begin{array}{l}\text { Cavernous sinus } \\
\text { involvement }\end{array}$ & $(0.006)$ & $\begin{array}{l}\text { DI 3.8204 } \\
(0.041)\end{array}$ \\
\hline $\begin{array}{l}\text { Postoperative } \\
\text { hormone dysfunction }\end{array}$ & - & $\begin{array}{l}8.6759 \\
(0.008)\end{array}$ \\
\hline $\begin{array}{l}\text { Postoperative } \\
\text { visual acuity }\end{array}$ & - & \\
\hline
\end{tabular}

Results reported as odds ratio ( $p$-value). The first column represents the independent variables and the first row represents the dependent variables in the analysis. Bolded findings indicate significance.

Table 6 Visual outcomes with time to surgery

\begin{tabular}{|l|l|l|l|l|l|}
\hline $\begin{array}{l}\text { Time to } \\
\text { surgery }\end{array}$ & $\boldsymbol{n}(\%)$ & \multicolumn{2}{|l|}{$\begin{array}{l}\text { Visual field } \\
\text { deficits } \\
(\boldsymbol{n}=16)^{\mathrm{a}}\end{array}$} & \multicolumn{2}{|l|}{$\begin{array}{l}\text { Visual acuity } \\
\text { deficits } \\
(\boldsymbol{n}=9)^{\mathrm{b}}\end{array}$} \\
\cline { 3 - 6 } & $\begin{array}{l}\text { Stable } \\
(n=3)\end{array}$ & $\begin{array}{l}\text { Improved } \\
(n=13)\end{array}$ & $\begin{array}{l}\text { Stable } \\
(n=3)\end{array}$ & $\begin{array}{l}\text { Improved } \\
(n=6)\end{array}$ \\
\hline$<48$ hours & $\begin{array}{l}37 \\
(84 \%)\end{array}$ & 3 & 9 & 3 & 5 \\
\hline$>48$ hours & $\begin{array}{l}7 \\
(16 \%)\end{array}$ & 0 & 4 & 0 & 1 \\
\hline
\end{tabular}

${ }^{\mathrm{a}} 16 / 44$ (36\%) patients had impaired visual fields at presentation. b9/44 (20\%) patients had impaired visual acuity at presentation.

A total of $29 \%$ of patients had no long-term hormonal deficit, but nearly as many patients (25\%) developed lasting panhypopituitarism. Other abnormalities included isolated hypothyroidism (22\%), diabetes insipidus (20\%, although only a little under one-third of these were lasting), hypocortisolism (12\%), and low testosterone (6\%). When evaluating each hormone, low testosterone hypothyroidism tended to resolve the most after surgery ( $91 \%$ of presenting cases), followed by hypothyroidism (77\% of presenting cases). At $22 \%$ of our population, panhypopituitarism was the most frequently acquired hormonal abnormality.

We evaluated the predictors of postoperative panhypopituitarism, postoperative diabetes insipidus, and postoperative adrenal insufficiency, as these were the hormonal deficits most prevalent postoperatively. Patient age $(p=0.057)$, BMI $(p=0.070)$, and ischemic apoplexy $(p=0.098)$ trended with higher odds of postoperative panhypopituitarism on univariate analysis although did not reach statistical significance ( - Table 4). There were no predictors of postoperative diabetes insipidus on univariate analysis. In contrast to the univariate analyses, there were no predictors of postoperative hormone dysfunction on multivariate analysis (-Table 5 ).

\section{Complications}

In eight patients, there were seven medical complications and one surgical complication identified in our series. Medical 
complications included readmission for hyponatremia or panhypopituitarism management, sepsis, transient atrial fibrillation with rapid ventricular response, seizure, and myocardial infarction. The most serious complication was intraventricular hemorrhage after resumption of therapeutic anticoagulation due to a recent pulmonary embolus; this required placement of an external ventricular drain, which was subsequently complicated by intraparenchymal hemorrhage that required a craniotomy for evacuation. Another patient required ventriculoperitoneal shunt placement after failure to wean off an external ventricular drain, which had been placed at presentation due to intraventricular hemorrhage. A postoperative cerebrospinal fluid leak occurred in one patient and resolved with bedrest.

\section{Duration of Hospitalization}

Patients presenting to our institution with pituitary apoplexy had a median overall length of stay (LOS) of 4 days. For those patients who had medical or surgical complications, the median LOS was 7.5 days with maximal LOS of 27 days. Anticoagulation use $(p=0.001)$, CSF leak $(p=0.025)$, and postoperative VA deficits $(p=0.035)$ were associated with a longer hospitalization on univariate analysis (-Table 4). Similarly, anticoagulation use (OR: 6.43, $p=0.011$ ), postoperative diabetes insipidus (OR: $3.82, p=0.041$ ), and postoperative VA deficits (OR: $8.68, p=0.008$ ) were independent predictors of an increased LOS on multivariate analysis (-Table $\mathbf{5}$ ).

\section{Bayesian Analysis of the Meta-Analysis}

We pooled our data with the meta-analysis of 12 articles available for review that documented preoperative VF deficits and $\mathrm{CN}$ palsies and outcomes of these deficits postoperatively. There was a total of 506 patients, 318 treated surgically and 188 treated conservatively. We added our series to this for a total of 366 surgically treated patients. We then created a composite vision deficit variable, as many of the studies did not stratify visual deficits by VA or VF deficits, to include our component of VA. In the surgical arm, of the 241 patients with a visual deficit, 64 had a residual deficit postoperatively. In the conservative arm, of the 61 patients with a visual deficit, 29 had residual visual deficits. Regarding CN palsies, the surgical group had 164 patients with palsies, of which 47 had residual deficits. In the conservative group, 9 of 75 patients had residual palsies.

Bayesian inference revealed a probability of visual deficit improvement of $48.2 \%$ in the surgical arm versus $17.9 \%$ in the conservative arm. The difference in probabilities had a mean of $30.3 \%$, with a credible interval ( $94 \%$ highest posterior density) of 0.226 to 0.369 . This represents an absolute risk reduction of 0.303 and a number needed to treat of 3.30 for visual improvement for surgery compared with no surgery. Said another way, surgery has an additional $30 \%$ chance of visual improvement compared with medical therapy alone. There was no difference in the effect on $\mathrm{CN}$ palsies between the two groups.

\section{Discussion}

Here, we present our institutional series of pituitary apoplexy patients who demonstrated excellent recovery of $\mathrm{CN}$ palsies and VF defects with early decompression of the optic apparatus; $82 \%$ of VF deficits and $100 \%$ of cranial neuropathies improved after surgery. In contrast, VA impairment at presentation was more resistant to improvement. Postoperative VA deficits depended only on preoperative VA deficits, suggesting the deficit is acquired from the apoplectic event and not the surgery. The $30 \%$ risk reduction of vision impairment we identified through pooled analysis advocates for early decompression in the setting of a visual or $\mathrm{CN}$ deficit, as loss of vision is associated with significant morbidity and decreased quality of life. ${ }^{22-25}$

Moreover, our series suggests that many hormonal abnormalities normalize following surgery, although panhypopituitarism commonly arises. While the prevalence of hypothyroidism is estimated at $3.7 \%$ in the United States, ${ }^{26}$ our data showed $41 \%$ of patients with thyroid dysfunction at presentation. The general incidence of low testosterone is estimated from 25 to $38 \%$ in the general population, ${ }^{27,28}$ so it is difficult to interpret our incidence of $25 \%$ in this context, although postoperatively low testosterone was only present in $6 \%$. Postoperatively, the most common deficit was panhypopituitarism at $25 \%$ followed by hypothyroidism at $22 \%$, and $6 \%$ needed long-term desmopressin for diabetes insipidus while $18 \%$ had transient DI. These findings are consistent with prior publications. ${ }^{13}$ We did not find any specific predictor of postoperative hormonal deficits. Indeed, the rate of hormone dysfunction requiring long-term replacement in our apoplectic patients (72.7\%) was much higher than our previously reported series of elective pituitary adenoma cases (27.5\%). ${ }^{29}$

We found larger tumor volume and cavernous sinus involvement, regardless of carotid encasement, was significantly associated with residual volume; suprasellar extension, however, was not. In pituitary apoplexy, decompression of the optic apparatus and maximal safe resection via a transsphenoidal approach for vision preservation is the goal of surgery. Whether it is necessary to utilize expanded endonasal corridors in the coronal plane to pursue tumor in the cavernous sinus is subject to debate. Our mean follow-up time was limited at 3.5 years with 1 patient having a recurrence 8 years from surgery that did have residual cavernous sinus disease. Other studies have estimated the rate of recurrence to be higher with $4.3 \%$ at 2 years and $13 \%$ at 5 years. ${ }^{30}$ However, this study mentioned only that subtotal resection was performed without comment regarding cavernous sinus disease. While these results suggest such recurrence is rare but not uncommon, the decision to aggressively pursue disease in the cavernous sinus must be individualized based on an appropriate risk/benefit calculation by the operating surgeon.

While most patients with early decompression had a short hospital stay, complications nearly doubled the LOS; these complications were most often medical in nature. Other predictors of longer LOS were postoperative CSF leak, postoperative diabetes insipidus, postoperative VA deficit, and chronic anticoagulation use prior to surgery.

With our technique, we encountered minimal CSF leak despite a high-mean BMI and nearly all cases having suprasellar extension. The leak rate in our study (2\%) is comparable to published reports. ${ }^{11,31,32}$ For the one patient with a 
postoperative CSF leak, surgical closure utilized Durepair (Medtronic) and TISSEEL (Baxter Healthcare); a KLS Martin Resorb-X plate was not used. This leak resolved with bedrest alone. We adopted the KLS Martin Resorb-X plate for rigid skull base reconstruction approximately halfway through this review's time period. While our cohort size is inadequate to accurately compare CSF leak rates based on reconstruction method, we have yet to encounter a CSF leak after pituitary apoplexy with our new closure technique.

While many providers typically advocate for multilayer closure including fat graft or nasoseptal flap, we demonstrate that our previously described rigid buttress technique ${ }^{33}$ is a suitable skull base reconstruction method even in obese patients. Harvesting a fat graft or nasoseptal flap requires an abdominal incision and taking down the mucosal lining of the nasal septum, respectively, both of which have associated complications that do not occur with the rigid buttress technique. These complications include seroma and hematoma formation at the fat graft site, septal perforation, septal flap necrosis, and prolonged nasal crusting following a nasoseptal flap. ${ }^{34}$ Moreover, with a mean BMI approaching 35 , the majority of our patient population is obese, which previously was shown to dramatically increase the risk of CSF leaks. ${ }^{35}$ This further suggests that our rigid buttress technique is robust in its closure with fewer complications than common alternatives.

It is interesting to note that our patients had a $16 \%$ complication rate that was largely medical in nature. The medical complications during the postoperative course have been underreported in the literature and may reflect a bias in most surgical outcome reports against discussing or assessing medical complications. This is an important limitation in the body of literature, as medical complications were more common than surgical complications in our series.

As discussed previously, there is still extensive debate between conservative and aggressive management strategies in pituitary apoplexy. Several recent publications have advocated for conservative management. Ayuk et al identified 33 patients in a 20-year period who presented with apoplexy, ${ }^{5} 16$ of which were treated surgically. Mean time to surgery from presentation was 4 days, with all being operated upon within 22 days. They evaluated VF and ocular palsies but did not evaluate VA. In the surgery group, VFs improved in $4 / 7$ patients (57\%) and ocular palsies resolved in 5/8 (63\%); they found $100 \%$ recovery in both domains in the conservative group. Both groups had comparable long-term hormone dysfunction. ${ }^{5}$

Seo et al reported 32 patients managed conservatively and evaluated visual and hormonal improvement as well as tumor volume and regression over time. ${ }^{6}$ They found that 18 of 32 subjects had visual disturbances, defined as deficits in acuity, field defects, diplopia, and CN palsies, with improvement in all but one. Total 19 patients had hormonal deficiencies on initial presentation and three additional patients acquired hormone deficits during follow-up, with 14 of 22 subjects having more than one hormonal abnormality at last endocrine evaluation.

A meta-analysis performed by Tu et al included six articles containing 98 patients treated surgically and 102 patients treated conservatively. ${ }^{19}$ They found that surgery favored VF recovery (OR: 0.32 [0.10-0.97], $p=0.04$ ) and ocular palsy (OR: 0.17 [0.03-0.79], $p=0.02$ ) with no difference in VA(OR: 0.37 [0.08-1.66], $p=0.19$ ) or hormone function (OR: 0.74 [0.37-1.48], $p=0.40$ ).

Sahyouni et al performed a meta-analysis of visual outcomes following early versus late surgery; they combined 12 articles for a total of 200 patients. $^{7}$ They defined early surgery as within 7 days of presentation and late surgery as after 7 days. To account for heterogeneity between the included studies, the meta-analysis combines all vision outcome variables (acuity, anopsia, ophthalmoplegia, ptosis, and diplopia) into a binary "visual recovery" variable. In this analysis, vision outcomes trended toward improvement with early surgery without reaching significance (OR: 2.619 [0.938-7.312], $p=0.07$ ). Although this does not appear to strongly favor early intervention, one could argue that treatment within 7 days of symptom onset may be too late of a time cutoff, as the optic apparatus may not be able to recover from a serious insult after a full week without decompression.

Recently, Almeida et al performed a review of their series and literature review and meta-analysis regarding surgical versus medical management. ${ }^{21}$ They stratified their surgical group into early versus late surgery, defined at the 72-hour mark, and found no difference between groups in regard to "visual decline" that did not distinguish between acuity or anopsia. They also found no difference in outcomes between surgery and conservative management, although they did find more severe deficits in the surgery group. Their metaanalysis found no difference in the odds-ratio between surgical and conservative arms in regards to complete VF recovery or $\mathrm{CN}$ palsies.

We pooled our data with the data in the Almeida et al metaanalysis and conducted Bayesian inference to evaluate our addition to the current published body of literature that adds an additional $15 \%$ of patients. In regards to visual deficits, we found an absolute risk reduction in persistent visual deficits of $30 \%$ with surgery compared with maximal medical management. This represents a number needed to treat of 3.3 for best visual improvement in pituitary apoplexy.

These studies suggest that regardless of management strategy, endocrine dysfunction is common and that the question for or against surgery is reserved in situations of "mild" visual dysfunction. Our aggressive early surgical management demonstrates marked clinical improvement in patients with VF deficits and cranial neuropathies, and was generally favorable, albeit less so, for VA deficits. This may suggest that the optic nerve is more sensitive to the mass effect of the apoplectic event than the optic chiasm/tract or adjacent CNs.

One patient in our series is quite illustrative of the concern for delayed surgery. She was admitted with headache alone without visual deficit despite having suprasellar extension of the tumor with the plan for optimization for next day surgery. However, that evening she developed proptosis, worsening headache, and declined to nonlight perception in the left eye with imaging depicting apoplectic expansion; she was subsequently emergently taken for decompression. 
She has long-term loss of light perception in the left eye. While this is one patient, in our series it represents a $2 \%$ chance of permanent blindness without urgent decompression upon initial evaluation. Since this case index, decompression is recommended for any apoplectic patient with suprasellar extension regardless of visual deficit to prevent clinical worsening.

\section{Implications}

This retrospective study suggests early surgical decompression may be a key strategy to optimize visual outcomes in pituitary apoplexy. We especially advocate for early surgery in patients who present with visual deficits. While many hormonal deficits improve after surgery, panhypopituitarism commonly arises and should be anticipated. When time permits, patients should be counseled about this prior to surgery; however, given that hormones can be replaced while vision cannot, we do not believe this should deter one from surgery. Early surgical management via the endoscopic endonasal transsphenoidal approach is associated with a short LOS. While the surgery is well tolerated, medical complications can be common and are frequently a result of endocrine disturbances.

\section{Limitations}

Our study is retrospective in nature and lacks the control of a prospective study. While our patient series is only 48 patients over 15 years, this is consistent with other series in a similar timeframe at a major academic referral center ${ }^{13,18,36}$ and as such likely has generalizability. Time to surgery is limited as it is a reflection of time to presentation and not time since symptom onset; however, in general patients with more severe deficits presented sooner and typically within 48 hours. Multivariate analysis is limited by the small sample size and unbalanced outcomes data; in particular, we could not identify predictors of visual outcomes because the majority of patients improved. Objective neuro-ophthalmology documentation is not available at follow-up in all cases. We infer with limitations that the immediate decompression resulted in the drastic improvement in CN palsies and visual outcomes, as we lack a control group of patients who did not undergo surgery. Our Bayesian estimation is a reflection of pooled statistics and should not be considered as a methodic Bayesian network meta-analysis of the literature.

\section{Conclusion}

Headache, cranial neuropathy, and vision complaints are the classic triad with pituitary apoplexy presentation and laboratory testing frequently reveals hormonal deficits. Prompt surgical intervention yielded excellent vision results. Longterm hormonal dysfunction necessitating medical replacement is common. By pooling our data with that from a previously published meta-analysis, we found a $30 \%$ absolute risk reduction in persistent visual deficits for surgery com- pared with medical management alone, corresponding to a number needed to treat of 3.3. Although some patient characteristics were associated with panhypopituitarism such as age and BMI, long-term hormonal problems are generally unpredictable. Cavernous sinus involvement was the only preoperative imaging feature associated with residual tumor. Despite a cohort that is nearly morbidly obese on average, our CSF leak rate was small and within standard ranges.

Conflict of Interest

None declared.

\section{References}

1 Fernandez A, Karavitaki N, Wass JA. Prevalence of pituitary adenomas: a community-based, cross-sectional study in Banbury (Oxfordshire, UK). Clin Endocrinol (Oxf) 2010;72(03):377-382

2 Wakai S, Fukushima T, Teramoto A, Sano K. Pituitary apoplexy: its incidence and clinical significance. J Neurosurg 1981;55(02): 187-193

3 Bonicki W, Kasperlik-Załuska A, Koszewski W, Zgliczyński W, Wisławski J. Pituitary apoplexy: endocrine, surgical and oncological emergency. Incidence, clinical course and treatment with reference to 799 cases of pituitary adenomas. Acta Neurochir (Wien) 1993;120(3-4):118-122

4 Lemos J, Eggenberger E. Neuro-ophthalmological emergencies. Neurohospitalist 2015;5(04):223-233

5 Ayuk J, McGregor EJ, Mitchell RD, Gittoes NJ. Acute management of pituitary apoplexy-surgery or conservative management? Clin Endocrinol (Oxf) 2004;61(06):747-752

6 Seo Y, Kim YH, Dho YS, et al. The outcomes of pituitary apoplexy with conservative treatment: experiences at a single institution. World Neurosurg 2018;115:e703-e710

7 Sahyouni R, Goshtasbi K, Choi E, et al. Vision outcomes in early versus late surgical intervention of pituitary apoplexy: metaanalysis. World Neurosurg 2019;127:52-57

8 Nawar RN, AbdelMannan D, Selman WR, Arafah BM. Pituitary tumor apoplexy: a review.J Intensive Care Med 2008;23(02):75-90

9 Semple PL, Webb MK, de Villiers JC, Laws ER Jr. Pituitary apoplexy. Neurosurgery 2005;56(01):65-72, discussion 72-73

10 Sibal L, Ball SG, Connolly V, et al. Pituitary apoplexy: a review of clinical presentation, management and outcome in 45 cases. Pituitary 2004;7(03):157-163

11 Yang T, Bayad F, Schaberg MR, et al. Endoscopic endonasal transsphenoidal treatment of pituitary apoplexy: outcomes in a series of 20 patients. Cureus 2015;7(10):e357

12 Lubina A, Olchovsky D, Berezin M, Ram Z, Hadani M, Shimon I. Management of pituitary apoplexy: clinical experience with 40 patients. Acta Neurochir (Wien) 2005;147(02):151-157, discussion 157

13 Singh TD, Valizadeh N, Meyer FB, Atkinson JL, Erickson D, Rabinstein AA. Management and outcomes of pituitary apoplexy. J Neurosurg 2015;122(06):1450-1457

$14 \mathrm{Kim} \mathrm{YH}$, Cho YH, Hong SH, et al. Postoperative neurologic outcome in patients with pituitary apoplexy after transsphenoidal surgery. World Neurosurg 2018;111:e18-e23

15 Hage R, Eshraghi SR, Oyesiku NM, et al. Third, fourth, and sixth cranial nerve palsies in pituitary apoplexy. World Neurosurg 2016;94:447-452

16 Woo HJ, Hwang JH, Hwang SK, Park YM. Clinical outcome of cranial neuropathy in patients with pituitary apoplexy. J Korean Neurosurg Soc 2010;48(03):213-218

17 Abdulbaki A, Kanaan I. The impact of surgical timing on visual outcome in pituitary apoplexy: literature review and case illustration. Surg Neurol Int 2017;8:16 
18 Rutkowski MJ, Kunwar S, Blevins L, Aghi MK. Surgical intervention for pituitary apoplexy: an analysis of functional outcomes. J Neurosurg 2018;129(02):417-424

19 Tu M, Lu Q, Zhu P, Zheng W. Surgical versus non-surgical treatment for pituitary apoplexy: a systematic review and metaanalysis. J Neurol Sci 2016;370:258-262

20 Leyer C, Castinetti F, Morange I, et al. A conservative management is preferable in milder forms of pituitary tumor apoplexy.J Endocrinol Invest 2011;34(07):502-509

21 Almeida JP, Sanchez MM, Karekezi C, et al. Pituitary apoplexy: results of surgical and conservative management clinical series and review of the literature. World Neurosurg 2019;130: e988-e999

22 David NJ. Pituitary apoplexy goes to the bar: litigation for delayed diagnosis, deficient vision, and death. J Neuroophthalmol 2006; 26(02):128-133

23 Wittenborn JS, Zhang X, Feagan CW, et al; Vision Cost-Effectiveness Study Group. The economic burden of vision loss and eye disorders among the United States population younger than 40 years. Ophthalmology 2013;120(09):1728-1735

24 Taipale J, Mikhailova A, Ojamo M, et al. Low vision status and declining vision decrease health-related quality of life: results from a nationwide 11-year follow-up study. Qual Life Res 2019;28 (12):3225-3236

25 Garcia GA, Khoshnevis M, Gale J, et al. Profound vision loss impairs psychological well-being in young and middle-aged individuals Clin Ophthalmol 2017;11:417-427

26 Aoki Y, Belin RM, Clickner R, Jeffries R, Phillips L, Mahaffey KR. Serum TSH and total T4 in the United States population and their association with participant characteristics: National Health and Nutrition Examination Survey (NHANES 1999-2002). Thyroid 2007;17(12):1211-1223
27 Mulligan T, Frick MF, Zuraw QC, Stemhagen A, McWhirter C. Prevalence of hypogonadism in males aged at least 45 years: the HIM study. Int J Clin Pract 2006;60(07):762-769

28 Araujo AB, O'Donnell AB, Brambilla DJ, et al. Prevalence and incidence of androgen deficiency in middle-aged and older men: estimates from the Massachusetts Male Aging Study. J Clin Endocrinol Metab 2004;89(12):5920-5926

29 Graham SM, Iseli TA, Karnell LH, Clinger JD, Hitchon PW, Greenlee JD. Endoscopic approach for pituitary surgery improves rhinologic outcomes. Ann Otol Rhinol Laryngol 2009;118(09):630-635

30 Pal A, Capatina C, Tenreiro AP, et al. Pituitary apoplexy in nonfunctioning pituitary adenomas: long term follow up is important because of significant numbers of tumour recurrences. Clin Endocrinol (Oxf) 2011;75(04):501-504

31 Zoli M, Milanese L, Faustini-Fustini M, et al. Endoscopic endonasal surgery for pituitary apoplexy: evidence on a 75-case series from a tertiary care center. World Neurosurg 2017;106:331-338

32 Paluzzi A, Fernandez-Miranda JC, Tonya Stefko S, Challinor S, Snyderman CH, Gardner PA. Endoscopic endonasal approach for pituitary adenomas: a series of 555 patients. Pituitary 2014;17 (04):307-319

33 Potter NJ, Graham SM, Chang EH, Greenlee JD. Bioabsorbable plate cranial base reconstruction. Laryngoscope 2015;125(06):1313-1315

34 Soudry E, Psaltis AJ, Lee KH, Vaezafshar R, Nayak JV, Hwang PH. Complications associated with the pedicled nasoseptal flap for skull base reconstruction. Laryngoscope 2015;125(01):80-85

35 Dlouhy BJ, Madhavan K, Clinger JD, et al. Elevated body mass index and risk of postoperative CSF leak following transsphenoidal surgery. J Neurosurg 2012;116(06):1311-1317

36 Ogawa Y, Niizuma K, Mugikura S, Tominaga T. Ischemic pituitary adenoma apoplexy-Clinical appearance and prognosis after surgical intervention. Clin Neurol Neurosurg 2016;148:142-146 